\title{
Provinha Brasil e avaliação formativa: um diálogo possível?
}

\section{The Brazilian standardized test for second grade students and formative assessment: a possible dialogue?}

\author{
Benigna Maria de Freitas Villas Boas ${ }^{1}$ \\ Elisângela Teixeira Gomes Dias²
}

\begin{abstract}
RESUMO
Este texto apresenta parte dos resultados de uma pesquisa referente ao processo desencadeado pela aplicação da Provinha Brasil em uma escola de Ensino Fundamental. As pesquisadoras acompanharam o trabalho desenvolvido pelos gestores da escola, coordenadores e professores, em especial as docentes das quatro turmas de $2^{\circ}$ ano do Ensino Fundamental. Identificaram-se concepções distintas em relação ao uso da Provinha Brasil decorrentes do processo de microrregulação local. Tais concepções revelam que o instrumento ora era tomado como mecanismo de exclusão, com foco no resultado final do teste, ora era tido como um mecanismo de inclusão dentro do espaço escolar, sendo um indicador do processo avaliativo que favorece a tomada de decisão. No estudo empreendido, partiu-se do pressuposto de que a Provinha Brasil pode contribuir para a melhoria do processo de ensino-aprendizagem se for compreendida no interior das instituições educacionais e pelas políticas públicas e articulada com a avaliação da aprendizagem via avaliação institucional. Entendeu-se que a questão central não reside na negação da avaliação externa, mas no uso que se faz dela. Todavia, não se desconsiderou que as políticas públicas educacionais e as dinâmicas escolares refletem processos sociais constituídos a partir dos interesses vigentes na sociedade.
\end{abstract}

Palavras-chave: Provinha Brasil; avaliação externa; avaliação da aprendizagem; avaliação formativa.

DOI: $10.1590 / 0104-4060.41421$

1 Universidade de Brasília. Departamento de Métodos e Técnicas. Programa de Pós-Graduação: Desenvolvimento Profissional Docente. Brasília, Distrito Federal, Brasil. Via L3 Norte, Área 1, 12. CEP: 70096900.E-mail: mbboas@terra.com.br

2 Faculdade LS. Taguatinga Sul, Distrito Federal, Brasil. Setor D Sul Lote 5. CEP: 72.020111. E-mail: elisangelagomesdias@gmail.com 


\begin{abstract}
This article presents part of the research findings related to the process unleashed by the administration of the Brazilian standardized test for second grade students in an Elementary School. The researchers followed the work developed by the school staff, coordinators and teachers, specially the elementary second grade teachers of four classrooms. They identified different conceptions about the use of the Brazilian standardized test due to the local micro-regulation process. The conceptions revealed that the test sometimes was viewed as an exclusion mechanism, focused on the results and other times it was viewed as an inclusion mechanism inside the school environment, as an indicator of the assessment process which promotes decision-making. In our study we adopted the idea that the Brazilian standardized test for second grade students can contribute to improve the teaching-learning process if understood within the school work and by public policies and articulated with learning assessment as part of the institutional evaluation. The central issue was not to deny external evaluation, but to emphasize how to use its results. However, we considered that the public educational policies and the school dynamics reflect social processes constituted by social interests.
\end{abstract}

Keywords: Brazilian standardized test for the second grade students; external evaluation; learning assessment; formative assessment.

\title{
Por que pôr em foco a Provinha Brasil?
}

Uma das iniciativas do Governo Federal para melhorar a qualidade da Educação Básica foi a ampliação do Ensino Fundamental para nove anos (Lei $\mathrm{n}^{\mathrm{o}}$ 11.274, de 06 de fevereiro de 2006), com matrícula obrigatória a partir dos seis anos. Além disso, o Ministério da Educação (MEC) implementou o Plano de Metas Compromisso Todos pela Educação. Uma de suas diretrizes expressa a necessidade de se alfabetizarem as crianças até os oito anos de idade, aferindo os resultados por meio de exame periódico. Para isso foi criada a Provinha Brasil, realizada em dois momentos durante o ano letivo: no início e ao final do segundo ano de escolarização.

Os itens da prova são corrigidos pelo próprio professor da turma ou pelo seu aplicador. A intenção é que os professores conheçam imediatamente a situação de aprendizagem dos seus alunos e possam promover as intervenções necessárias. Sugere-se ainda que os gestores recolham os dados obtidos nos testes para que possam contar com elementos para subsidiar a formulação das políticas educacionais. 
Em linhas gerais, a Provinha Brasil diferencia-se dos demais testes porque os seus resultados não são utilizados na composição do Índice de Desenvolvimento da Educação Básica (IDEB). Além disso, ela fornece respostas diretamente aos alfabetizadores e gestores das instituições educacionais, corroborando a sua intenção diagnóstica. Por isso o Instituto Nacional de Estudos e Pesquisas Educacionais Anísio Teixeira (INEP) disponibiliza anualmente duas versões do teste, uma para ser aplicada no início do ano letivo e a outra ao término do segundo ano de escolarização, a fim de identificar os níveis de desempenho das crianças. A aplicação em períodos distintos possibilita aos professores e gestores a realização de diagnóstico mais preciso e em tempo real, permitindo que o coletivo da escola identifique o que foi agregado em relação às habilidades avaliadas no período pelo fato de o teste fornecer parâmetros de comparação dos resultados dos mesmos estudantes.

$\mathrm{O} \mathrm{MEC} / \mathrm{INEP}$ recomenda que as informações produzidas pela Provinha Brasil ajudem as instituições educacionais na elaboração e (re)orientação de planejamentos e ações que visem à melhoria da qualidade da alfabetização, o que incide sobre o desenvolvimento do currículo e do projeto pedagógico da escola como um todo. Para tanto, espera-se que possam ser definidas metas pedagógicas e administrativas pelas secretarias de educação que resultem na implementação de ações concretas e sistemáticas para auxiliar as escolas e os professores a alcançarem o que deles se espera.

A influência das universidades que integram a Rede Nacional de Formação Continuada de Professores da Educação Básica do MEC foi determinante para que a Provinha Brasil tivesse esse formato. A concepção de avaliação formativa orientou o processo de elaboração do instrumento desde o início. As decisões foram tomadas em colegiado e houve muita interlocução. (DIAS, 2014).

Levando em conta os pressupostos da Provinha Brasil, este texto tem o propósito de analisar as possibilidades de ela manter diálogo com a avaliação formativa. Para alcançarmos este objetivo, apresentamos parte dos resultados de uma pesquisa que buscou compreender as implicações da utilização da Provinha Brasil no trabalho pedagógico da rede pública de ensino do Distrito Federal (DF). (DIAS, 2014). A pesquisa considerou o contexto educativo dos professores que aplicam a Provinha Brasil e sua interação com os demais profissionais da instituição e com as crianças, em diferentes espaços/atividades: salas de aula, atividades de planejamento, reuniões de conselho de classe, reuniões com os pais ou responsáveis e reuniões ou eventos organizados pelos gestores da Secretaria de Educação do DF (SEEDF). Para isso, vários procedimentos foram utilizados: análise documental, observação participante, entrevistas semiestruturadas e questionários. 
Neste texto abordaremos parte dos resultados obtidos ainda na fase preliminar da pesquisa, referentes ao processo desencadeado pela aplicação da Provinha Brasil em uma escola de Ensino Fundamental da rede pública de ensino do Distrito Federal, nos anos de 2011 e 2012. As pesquisadoras acompanharam o trabalho desenvolvido pelos gestores da escola, coordenadores e professores, em especial das docentes das quatro turmas de $2^{\circ}$ ano do Ensino Fundamental.

Antes de descrevermos esse processo, pontuamos no item seguinte as possibilidades de aproximação deste instrumento com a avaliação formativa.

\section{Aproximando a Provinha Brasil da avaliação formativa}

A avaliação das aprendizagens é o nível da avaliação mais conhecido, talvez pelo fato de ela sempre ter sido autoritária, seletiva e excludente, o que lhe retirou, durante muito tempo, a possibilidade de ser questionada. Avaliar somente o estudante e apenas através do professor sempre foi a regra. A partir da década de 1990, com a criação dos exames em larga escala e, nos últimos anos, com a introdução da avaliação do trabalho da escola de educação básica, o campo da avaliação se alargou e novas exigências têm sido apontadas.

Dentre os exames em larga escala, a Provinha Brasil se destaca pela sua singularidade: é elaborada por pessoas externas à escola, mas é aplicada e corrigida pelos professores da escola e os seus resultados nela permanecem. Essa sistemática oportuniza à escola analisar todo o processo de desenvolvimento desse instrumento e, de modo particular, os resultados obtidos, para que, juntamente com as informações fornecidas pela avaliação praticada pelos professores, possibilitem o reconhecimento das necessidades de reorganização do trabalho pedagógico. Mas, é preciso lembrar: não se trata de preparar as crianças para a realização de provas. Testes externos à escola oferecem benefícios se trouxerem elementos que se somem à avaliação do dia a dia do trabalho de sala de aula. Essa junção de olhares constitui a intenção da avaliação formativa: promover as aprendizagens de cada criança.

Em um artigo em que analisam as três gerações de avaliação em larga escala, a partir dos objetivos e ações da sua implementação no Brasil, Bonamino e Sousa (2012) apresentam a primeira geração como a que realiza avaliação diagnóstica da qualidade da educação, sem a produção de consequências diretas para o trabalho pedagógico das escolas, no sentido de articulá-las a políticas de responsabilização, o que é feito pelas outras gerações, que atrelam os resultados dos exames a consequências simbólicas ou materiais para os atores escolares. 
Os resultados das avaliações de primeira geração são divulgados pela internet ou pela mídia, sem que sejam devolvidos à escola. O Sistema Nacional de Avaliação da Educação Básica (SAEB) é identificado como de primeira geração.

Explicam as autoras que as consequências simbólicas dessas políticas possuem baixo impacto (low stakes) ou atribuem responsabilização branda (esta é a segunda geração). Como exemplo dessa segunda geração, as autoras citam a Prova Brasil, que agrega à "perspectiva diagnóstica a noção de responsabilização". (BONAMINO; SOUSA, 2012). As consequências fortes (high stakes) conduzem à igualmente forte responsabilização (esta é a terceira geração). Este é o caso do Sistema de Avaliação do Rendimento Escolar do Estado de São Paulo (SARESP), que instituiu o Bônus Mérito.

Pelas suas características, a Provinha Brasil se aproxima do que Bonamino e Sousa (2012) denominam de avaliação em larga escala de primeira geração porque seu compromisso é com a avaliação diagnóstica. No entanto, seu foco não é a publicização dos resultados com a finalidade de pressionar a escola a promover melhoria em seus processos de ensino, uma estratégia fundamental das avaliações externas de primeira geração instituídas a partir da "teoria da responsabilização".

Mesmo sendo um instrumento padronizado e elaborado por pessoas externas à escola, a Provinha Brasil tem a finalidade de servir como mecanismo de avaliação interna, o que traz consequências diretas para o trabalho pedagógico das escolas. Além disso, é a única avaliação que disponibiliza duas versões do teste e possibilita que os seus resultados possam ser "consumidos" em tempo real, o que facilita a sua vinculação à função formativa, a serviço das aprendizagens dos estudantes, professores e com o desenvolvimento da escola. (VILLAS BOAS, 2011).

Orientações produzidas pelo MEC afirmam que a Provinha Brasil é " [...] instrumento pedagógico, sem finalidades classificatórias, que fornece informações sobre o processo de alfabetização aos professores e gestores das redes de ensino". (MEC, 2007). Mas, de que forma esse exame tem sido utilizado e regulado na dinâmica interativa da escola?

Vejamos, no item a seguir, os desdobramentos da aplicação da Provinha Brasil em uma escola da rede pública do Distrito Federal.

\section{O que pensam os professores em relação à Provinha Brasil: concepções tecidas na dinâmica interativa da escola}

$\mathrm{O}$ interesse em investigar um instrumento de avaliação externa como a Provinha Brasil está em compreender se ela pode ser implementada a partir da 
perspectiva de "qualidade negociada", defendida por Freitas (2007). Partimos do pressuposto de que este instrumento, se compreendido no interior das instituições educacionais e também pelas políticas públicas e articulado com a avaliação da aprendizagem via avaliação institucional, pode contribuir para a melhoria do processo de ensino-aprendizagem.

Entretanto, consideramos que a Provinha Brasil, mesmo anunciando objetivos voltados para uma avaliação diagnóstica e tendo uma metodologia diferente dos demais exames externos, se instaura em uma sociedade que é capitalista e em um momento histórico em que os exames aplicados em larga escala servem para classificar, excluir e segregar coletivos sociais. Como seus usos não podem ser controlados, o exame pode servir para reproduzir e manter as contradições dessa totalidade, reveladas em seus instrumentos e enlaces mediadores. Consideramos ainda o fato de que para a manutenção do sistema vigente, que atrela a qualidade da educação ao uso de exames externos, os fins da Provinha Brasil podem ser amplamente disseminados e interpretados a partir dessa lógica, na busca de um consentimento coletivo por parte daqueles que diretamente ou indiretamente se relacionam com este instrumento de avaliação.

A pesquisa realizada revelou que as concepções quanto à Provinha Brasil estão engendradas na dinâmica interativa da organização do trabalho pedagógico, pois as mudanças no campo educacional não acontecem de forma isolada, tampouco por força da retórica política e normativa. A escola, que é a unidade central do sistema educacional, não é apenas um lócus de reprodução da política educacional, mas, também, de sua produção na medida em que sua função e a própria concepção de educação são determinadas pela trama social. Com efeito, foi possível identificarmos concepções distintas em relação ao uso desse exame, fruto da microrregulação local, definida por Barroso (2006, p. 56) como “[...] um complexo jogo de estratégias, negociações e acções, de vários actores, pelo qual as normas, injunções e constrangimentos da regulação nacional são (re)ajustadas localmente, muitas vezes de modo não intencional". Tais concepções se constituem a partir dessa dinâmica interativa, sendo então necessária a compreensão do contexto em que os discursos foram produzidos.

a) Quando o foco é o resultado: avaliar para comparar e responsabilizar coletivos sociais

Em 2011, acompanhamos a aplicação e a divulgação dos resultados da Provinha Brasil durante a primeira e segunda fases dos testes de leitura e matemática. A pesquisa estava na fase exploratória, de forma que todos os registros foram feitos somente no diário de campo. Mas, em conversa constante com 
as professoras do segundo ano e com a supervisora pedagógica, foi possível apreendermos as concepções quanto à Provinha Brasil (PB).

Durante a primeira fase do teste, constatamos que as concepções acerca da PB eram bastante positivas. Todas as professoras afirmavam que ela era "eficiente", que realmente revelava o desempenho dos estudantes em relação aos conhecimentos avaliados. Era vista como indutora do que deveria ser ensinado, considerando sua relevância para o trabalho docente, como afirma a professora Margarida 3 : "A prova serve para nos orientar, porque às vezes a gente acha que está no caminho certo e deixamos conteúdos importantes de fora, como fizemos o ano passado [2010] com o Sistema Monetário.” (Prof ${ }^{a}$ Margarida, Informação oral, 07/06/2011). Havia, inclusive, uma visão de que o teste era um instrumento incontestável, conforme relato da professora Hortência:

Eu acho que as pessoas que fazem essas provas são iluminadas, porque elas são estudiosas e sabem o que estão fazendo. Elas não irão colocar na prova aquilo que não é necessário para ser ensinado. Elas sabem o que é melhor para a vida das crianças. Estudar essas provas aqui na escola é uma reciclagem para a gente, porque nós não temos tempo para buscarmos muitas coisas novas. E olha que estou sempre nos cursos da EAPE (Escola de Aperfeiçoamento dos Profissionais da Educação do Distrito Federal). A diferença é que vendo a prova sabemos como temos que fazer, o que trabalhar com os meninos, e nos cursos nem sempre é assim. Só o fato de ser uma avaliação já é válido. É importante porque facilita a intervenção do professor. (Prof ${ }^{a}$ Hortência, Informação oral, 07/06/2011).

Os dados fornecidos a partir da PB são apenas indicadores das habilidades avaliadas que precisam se integrar aos demais objetivos traçados pelo sistema educacional, pela escola e pelos professores com vistas à alfabetização das crianças. No entanto, o relato acima demonstra uma visão acrítica e simplista em relação aos testes padronizados, em especial a $\mathrm{PB}$, que defende veementemente em seus documentos o seu caráter diagnóstico. Depreendemos, pois, que a retórica oficial de que avaliação externa é sinônimo de qualidade do ensino, reforçada pela mídia, tem sido reproduzida no interior das escolas.

Entretanto, as professoras passam a desconfiar do teste quando o resultado da segunda fase é inferior ao da primeira. A mesma professora que havia

3 Nome fictício, assim como dos demais participantes da pesquisa. 
dito que o teste era "[...] um importante instrumento para acompanhar o nosso trabalho, bem elaborado e que realmente revela se a criança está ou não alfabetizada" (Prof Rosa, Informação oral, 07/06/2011), ao final do ano questiona sua validade afirmando que:

Uma prova dessas para as crianças é difícil. Os meninos são infantis. É frustrante para as crianças pequenas que ainda não sabem ler, e para os professores também. (Silêncio). Eu fiz muito, mas não para fazer uma avaliação como essa. Eu questiono é a Provinha para essas crianças que não estão alfabetizadas ainda, porque as outras até que dão conta. (Prof ${ }^{a}$ Rosa, Informação oral, 14/12/2011).

O caráter classificatório do teste, gerado pelas metas estabelecidas em relação aos níveis de desempenho da prova, ganha força. As professoras sentiram que foram julgadas e responsabilizadas pelo resultado do teste, de forma que todo o trabalho realizado durante o ano letivo não foi considerado. Denunciaram que os gestores não consideravam as especificidades de cada turma ao comparar os resultados da PB. A professora com menor desempenho na prova final ficou com baixa autoestima e pensou até em treinar as crianças para o próximo teste, ou mesmo falsear os dados, como pode ser percebido na continuidade do relato da professora Rosa:

O ano passado foi difícil. Eu tinha muitas crianças pré-silábicas no início do ano. A turma foi montada assim porque a outra turma era inclusiva e tinha crianças com Deficiência Mental e Sindrome de X Frágil. A minha turma ainda era muito indisciplinada, pois os alunos mais calmos ficaram com a outra professora, por isso o rendimento era diferente. Os meus alunos com dificuldade não vinham no reforço e ai eu tinha que fazer as intervenções com agrupamento em sala de aula, no horário da aula. Mas não consideraram nada disso no final do ano, quando fizeram a comparação dos resultados da Provinha Brasil com a outra turma. A direção me chamou para falar que a minha turma foi a pior! Isso me deixou triste. Eles [os alunos] cresceram, mas não a ponto de alcançar o quatro da Provinha [nivel esperado na segunda fase do teste] porque eles tiveram dificuldades de interpretar os textos. E olha que eu trabalhei textos demais. [...]. 
Essa comparação dos alunos não foi justa, e me fez pensar: será que eu vou ter que treinar os alunos agora para fazer a Provinha? Eu me senti mal. Cada criança tem um ritmo, uma maturidade. Eles eram indisciplinados, preguiçosos, não tinham interesse, mas parecia que a culpa era só minha. Foi eu que fracassei como professora! A remessa [de alunos] de 2011 foi dificil, eram desinteressados e os pais não ajudavam. Eu me desdobrava, fazia de tudo. Teve crescimento minha turma? Teve, mas não para fazer a Provinha Brasil. Eu planejava junto com a $B$ [a outra professora do $2^{\circ}$ ano], mais ela podia puxar mais. Os alfabéticos da minha sala se beneficiavam no momento dos agrupamentos. As crianças moram longe, não podiam vir para o reforço no horário contrário. Não faziam nem o dever de casa. Os cadernos vinham sujos. Eu reclamava com os pais e no outro dia era do mesmo jeito! Eu chorei com o resultado da Provinha Brasil. Fiquei arrasada! Me senti incompetente. Parece que o que eu fiz durante o ano todo não valeu nada. O resultado da segunda prova foi até pior que o da primeira. Eu acho que cobrar texto na PB não dá. Muitos alunos começam o ano sem saber ler nada. Por isso eu pensei: no ano que vem eu vou ser diferente, eu vou fazer os alunos gabaritarem a prova. (Prof ${ }^{\mathrm{a}}$ Rosa, Informação oral, 14/12/2011, grifo nosso).

Podemos perceber o constrangimento causado pela avaliação no interior da escola, tanto para a docente quanto para os estudantes. Há uma necessidade da professora em justificar o suposto "fracasso" e, para isso, ela responsabiliza o outro que, nesse caso, é o "mais fraco" da relação: a criança. Mesmo declarando que "cada um tem um ritmo diferente", o problema passa a ser a turma heterogênea, formada por crianças com "dificuldades" de aprendizagem, "indisciplinadas", "preguiçosas", "desinteressadas" e que ainda não frequentavam as aulas de reforço e não realizavam as tarefas de casa, pois as famílias pouco contribuíam.

O fato de a direção da escola chamar a professora para lhe dizer que a sua turma "era a pior" é grave: além de desqualificar seu trabalho, lhe oferecia inspiração para que fizesse o mesmo com seus estudantes. Observa-se que a professora Rosa faz referência aos "alfabéticos da minha sala". Esse formato de classificação pode conduzir os professores a não perceberem que a Provinha Brasil pode produzir outros tipos de classificação dependendo do uso que se faça dos seus resultados.

A responsabilidade pelo resultado não foi compartilhada com os outros atores da escola. A professora Begônia reconhece que não era possível comparar as turmas por várias razões, apontadas desde o início do ano para os gestores da escola, mas denuncia que ninguém fez nada. As crianças faltavam às aulas, eram 
indisciplinadas na sala, mas não houve nenhuma ação para ajudar o trabalho da professora Rosa. Por isso, sua percepção em relação à Provinha Brasil também havia mudado. Não em relação ao teste, mas em relação às suas possibilidades de uso. Ela afirma:

Ainda acho que o teste é um bom indicativo para o nosso trabalho [...]. Dizem que a Provinha Brasil é para apoiar o professor, mas não foi isso que fizeram com ela. Eles compararam mesmo. Aqui na escola e nas reuniões do CRA [Centro de Referência em Alfabetização] também. A "Rosa ficou até doente". (Prof Begônia, Informação oral, 14/12/2011).

Por sua vez, a supervisora pedagógica reconhece que o resultado das turmas na PB de 2011 foi diferenciado em função das especificidades das crianças, mas também busca no outro a responsabilidade pela queda no resultado do teste. Esse outro foram as professoras que atuavam no Centro de Referência em Alfabetização (CRA), por não terem orientado os professores regentes do $2^{\circ}$ ano para a aplicação da PB, e também as crianças da professora Rosa, consideradas "fraquinhas", conforme o relato a seguir:

Eu confesso que fiquei decepcionada. Eu esperava mais... Existe uma questão que tem que ser resolvida: o CRA não fez a preparação para a aplicação direto com os professores. Isso pode ter sido um fator que contribuiu para o baixo desempenho. Eu esperava mais. As turmas não renderam, e na psicogênese os meninos estavam muito bons. Eu estranhei. [...]. Tinha uma turma muito fraquinha. A professora ficava doente. A turma tinha muitos problemas de comportamento. Foi dificil para ela, eu sei. Mas a nossa escola não teve um resultado ruim, comparando com as escolas vizinhas. A daqui do lado teve um resultado ruim, o pior de todos. E olha que a comunidade é a mesma, é só virar a rua. Avalio que tivemos um bom resultado, mesmo sabendo que poderia ter sido ainda melhor. (Supervisora pedagógica, Informação oral, 15/03/2012, grifo nosso).

Os Centros de Referência em Alfabetização (CRA) têm papel preponderante na produção e disseminação de conhecimentos, experiências e pesquisas vinculadas a temáticas relevantes ao processo de alfabetização. Para isso, os professores que trabalham no CRA, chamados de "articuladores", acompanham em média 40 turmas do $1^{\circ}$ ao $3^{\circ}$ ano do Ensino Fundamental para atender às 
demandas dos coordenadores pedagógicos e dos professores atuantes no bloco. De acordo com as Diretrizes Pedagógicas do Bloco Inicial de Alfabetização (BIA) (DISTRITO FEDERAL, 2012), esses profissionais devem oferecer suporte técnico-pedagógico para elaboração de projetos, atuar na formação continuada, fomentar a formação de grupos permanentes de discussão sobre alfabetização, acompanhar o processo de alfabetização das crianças, entre outras ações. Entretanto, foi possível percebermos que a prática de ranqueamentos era feita pelo CRA não somente levando em conta os níveis da PB, mas também os resultados do teste da psicogênese.

A aplicação desse teste tem sido amplamente recomendada na rede pública de ensino e tem servido para monitoramento das aprendizagens das crianças que estão em turmas de alfabetização. As articuladoras recolhem o teste bimestralmente e divulgam os resultados em reuniões com coordenadores e supervisores pedagógicos, comparando os resultados das escolas, da mesma forma que fazem com os dados da Provinha Brasil. Segundo as coordenadoras da escola, há cobrança dos gestores para que as crianças avancem, mas a responsabilidade novamente é repassada somente para a escola. Embora os documentos orientadores do trabalho pedagógico das escolas da rede pública de ensino do DF assumam compromisso com a avaliação formativa, observa-se que práticas classificatórias parecem predominar.

Ao afirmar que o resultado de sua escola foi melhor do que os resultados da escola vizinha, a supervisora pedagógica possivelmente esteja reproduzindo o mesmo discurso oficial. A lógica difundida, portanto, continua sendo a máxima: avaliar para classificar e culpabilizar. Além disso, ao afirmar que não entende a razão de os resultados da PB não coincidirem com os do teste da psicogênese, a supervisora demonstra não compreender os fundamentos da PB pautados na concepção de que a alfabetização e o letramento são processos complementares e inseparáveis, entendimento presente nas últimas décadas. $O$ teste da psicogênese, feito a partir da aplicação de quatro palavras e uma frase, se restringe a avaliar o código escrito, enquanto a prova de leitura da PB avalia as habilidades referentes ao processo de leitura e interpretação de textos. Essa é uma discussão que merece ser ampliada, mas que não constitui objetivo do presente artigo.

Consideramos que, em decorrência da forma como o monitoramento das práticas escolares via exames externos tem sido feito, torna-se difícil para os professores distinguirem as diferentes finalidades dos instrumentos que têm chegado até a escola. Em linhas gerais, é possível percebermos que a política de responsabilização (accountability) composta, segundo Freitas (2011), por três elementos (medição do desempenho dos estudantes, publicização dos resultados e recompensa ou sanções baseadas em alguma medida de desempenho - pagamento por mérito) tem avançado nos estados e municípios e, 
consequentemente, para o interior das escolas e das salas de aulas. O mesmo fato também foi identificado em outras pesquisas (DIAS, 2010; MAIA, 2010; ESTEBAN; SAMPAIO, 2012), o que indica que o uso dos resultados da PB tem servido para comparar escolas e crianças, se distanciando das recomendações da política federal.

Ademais, a cultura da nota, e porque não dizer da classificação e da exclusão, ainda está tão arraigada que, mesmo adotando o instrumento oficial da SEEDF para registro das avaliações, o Relatório de Desempenho Individual dos Alunos (RDIA), todas as professoras acompanhadas pelas pesquisadoras aplicavam provas durante o bimestre e davam notas. Uma delas, ao ser questionada sobre o uso deste procedimento, justificou: "Os pais precisam da nota. $\mathrm{Na}$ verdade, é isso que importa para eles". (Prof ${ }^{a}$ Margarida, Informação oral, 19/04/2012).

Freitas (2002) afirma que mecanismos de resistência à lógica seriada e à avaliação classificatória e excludente, empreendidos por todos os atores que compõem a educação e aliados a movimentos sociais que lutam pela emancipação do homem, precisam ser pensados e instituídos. A escola continua sendo espaço de luta, por isso não se pode concluir que ela está irremediavelmente perdida. Dessa forma, entendemos que a presença marcante da avaliação em larga escala e suas implicações nos âmbitos político e pedagógico reivindicam a compreensão de como, para além de apresentações de resultados numa perspectiva de ranqueamentos das instituições, esse processo pode se articular com a avaliação das aprendizagens e a avaliação institucional de modo a contribuir para a melhoria do trabalho escolar.

\section{b) Quando o foco é a dinâmica do processo avaliativo: avaliar para intervir}

Em 2012 estivemos presentes na escola por um tempo mais longo, em média duas vezes por semana. Para que pudéssemos compreender melhor a dinâmica da organização do trabalho pedagógico da escola e das turmas do $2^{\circ}$ ano, participamos dos momentos de estudos, planejamentos e, sobretudo, analisamos juntamente com o grupo os resultados da Provinha Brasil aplicada em 2012. Foram momentos de mediação que se desenvolveram por considerarmos que, nos limites da sociedade atual e da organização da escola, "[...] a tomada de consciência a respeito da maneira como o processo de avaliação se dá e de suas relações com a organização do trabalho pedagógico" (FREITAS et al., 2009, p. 30-31) é uma ação positiva para superação de práticas avaliativas classificatórias e excludentes.

Em linhas gerais, identificamos vários fatores que interferiam e, ao mesmo tempo, constituíam a organização do trabalho escolar, especialmente em relação 
às práticas avaliativas. Eram fatores externos, decorrentes das políticas locais instituídas e interpretadas por gestores que atuavam no nível intermediário, e fatores internos, engendrados pela cultura escolar, formação, valores e crenças dos professores, modelo de gestão e condições social, cultural e econômica dos estudantes, entre outros. Pelas limitações do artigo e em razão do objetivo proposto, todo este pano de fundo não será explorado. Entretanto, é importante destacar que as reflexões feitas no interior da escola, com participação direta das pesquisadoras, consideraram toda essa dinâmica e contexto.

Assim, foi possível percebermos as mudanças de entendimento das possíveis contribuições da Provinha Brasil. À medida que compreendiam de forma ampla os resultados do teste e conseguiam refletir sobre o que significavam os acertos e os erros das crianças, as professoras e gestoras deixavam de focalizar o resultado final da prova. A forma de os resultados do teste serem apresentados e discutidos com o grupo também contribuiu para essa mudança. Tanto as professoras como a supervisora pedagógica e a coordenadora começaram a perceber que o processo avaliativo é revelador também do trabalho desenvolvido na escola, como exemplificam as falas abaixo:

Sabe, agora eu estou vendo com outros olhos os resultados de 2011. Eu sei que o nosso resultado poderia ter sido melhor. Então, eu pergunto: por que o resultado foi diferente? Acho que é porque ainda temos um trabalho tradicional. Temos uma cabeça em série, em cartilha, em ensino fora do texto. [...]. A PB é um instrumento que nos ajuda muito, pois tem intencionalidade. A de Português, por exemplo, mostrou que não estamos trabalhando a partir do texto, como eu já falei. É um instrumento com o objetivo de reorientar a prática pedagógica e não para ranquear os resultados. Precisamos sempre melhorar, estudar. O professor não consegue buscar sozinho, precisa de ajuda, de apoio. (Prof ${ }^{\mathrm{a}} \mathrm{Lis}$, supervisora pedagógica, Informação oral, 19/04/2012). Os estudos que estamos fazendo sobre o currículo, por exemplo, me fizeram compreender o que a Provinha Brasil avalia. Eu não entendia. Agora eu consigo ver o todo e entender que Lingua Portuguesa, por exemplo, não é só leitura e escrita de palavras. Precisamos nos apropriar do currículo, pois se não nos limitamos à prova. A lógica não é essa! (Prof ${ }^{a}$ Rosa, Informação oral, 07/06/2012). Eu era radical. Achava que a prova só servia para classificar os meninos, selecionar quem sabia. Hoje penso diferente, que a prova é somente um instrumento que avalia algumas coisas. O que fazemos com os resultados é que interessa. (Prof ${ }^{a}$ Hortência, Informação oral, 07/06/2012). 
Diferentemente dos relatos colhidos em 2011 e no início do ano letivo de 2012, tanto a supervisora pedagógica como a professora Rosa passam a perceber as implicações do trabalho desenvolvido na escola, deixando de atribuir somente ao outro, em especial às crianças, o sucesso ou fracasso pelos resultados alcançados no teste. Além disso, como indica a fala da professora Hortência, as limitações do instrumento passam a ser mencionadas, o que é relevante. Primeiro porque o teste, por estar restrito a uma matriz de referência e por sua característica (uma prova objetiva), não avalia todas as habilidades necessárias ao processo de alfabetização. Segundo, porque, ao estipular níveis de desempenho ideais e desejados, a PB abre a possibilidade de ranqueamentos de crianças, professores, escolas e redes de ensino.

É importante reiterar que as reflexões mediadas quanto ao uso da PB não ficaram restritas aos professores que aplicaram e corrigiram o teste. Todos os profissionais da escola foram envolvidos nas discussões, pois acreditamos que o coletivo da escola precisa constituir e solidificar práticas de avaliação institucional porque todos são responsáveis pelo trabalho pedagógico da escola. Ao final da reunião coletiva em que discutimos os dados gerados na primeira etapa do teste, foi solicitado o preenchimento de um questionário que revelou:

a) A compreensão classificatória dos exames externos foi contestada. Os professores destacaram a importância e necessidade de utilização dos testes para reorganização do trabalho pedagógico da escola, de forma articulada e sistematizada, conforme ilustram as assertivas abaixo:

[...] A reunião de hoje esclareceu vários aspectos relevantes acerca do que fazer com estes resultados [da PB], de como interpretá-los. "Aprendemos" a utilizar este instrumento para melhorarmos até mesmo a visão do nosso trabalho, não nos frustrar, nem culpar, mas direcionar o trabalho da escola. (Prof $\left.{ }^{\mathrm{a}} \mathrm{A}\right)$.

Percebemos que o foco não é preparar os alunos para a Provinha Brasil... A mediação amplia nossos conhecimentos, nos dando suporte para a tomada de decisões. (Prof $\left.{ }^{\mathrm{a}} \mathrm{B}\right)$.

Antes eu via a Prova Brasil [se referindo à Provinha Brasil] apenas como medidor de "qual escola é melhor" e "quais professores são mais capacitados". Hoje vejo essa avaliação como uma forma de melhorar o nosso trabalho. (Prof $\left.{ }^{a} \mathrm{C}\right)$. 
É preciso compreender que a Provinha Brasil veio para apoiar o trabalho do professor. Os resultados devem ser discutidos na escola, para que sua interpretação direcione para um trabalho que ajude os alunos que não alcançaram as habilidades apresentadas. (Prof $\left.{ }^{\mathrm{a}} \mathrm{D}\right)$.

b) O fato de as professoras afirmarem que a Provinha Brasil é um exame que pode oferecer contribuições para o desenvolvimento do trabalho pelo professor e pela escola não significa que elas não identifiquem as limitações do teste, como pode ser percebido nos registros a seguir:

Por mais que não avalie integralmente, a PB procura avaliar conteúdos condizentes com a realidade do currículo da série em questão. A partir dos resultados, pode-se elaborar estratégias pedagógicas... (Prof $\left.{ }^{\mathrm{a}} \mathrm{E}\right)$.

A PB ajuda sim no trabalho desenvolvido pela escola, mas ela não pode ser considerada como um único instrumento para a avaliação. Por meio da Provinha é possivel avaliar se o trabalho desenvolvido tem sido pautado no currículo ou se o professor tem se apropriado "dele" trabalhando apenas aquilo que considera importante. ( $\left.\operatorname{Prof}^{\mathrm{a}} \mathrm{F}\right)$.

Esses registros indicam que as professoras reconhecem o caráter diagnóstico do instrumento, sem desconsiderar suas particularidades. Nenhuma delas fez referência ao fato de a Provinha Brasil fornecer dados em tempo real e em dois momentos distintos: inicial e final. Entretanto, a maioria compreendeu que os resultados do teste são apenas indicadores que representam o trabalho de toda equipe e que cada escola precisa considerar o seu contexto.

c) Ao serem questionadas quanto à forma pela qual os dados dos exames externos devem ser utilizados pela escola e pela rede pública de ensino, as professoras foram enfáticas ao afirmar que os resultados não devem ser utilizados para classificar ou ranquear os estudantes, professores e escolas, e sim para favorecer o desenvolvimento das aprendizagens.

Como medidas pedagógicas que se destinam a diagnosticar e nunca para ranquear. E que possa ser um instrumento que considere os resultados 
como dados que norteiem, digo, que possibilitem um feedback para o professor atender os alunos ajudando a superar as dificuldades. ( $\left.\operatorname{Prof}^{a} \mathrm{H}\right)$.

Formativamente, a fim de rever "metodologias". Sem ranqueamento ou definições dos melhores alunos; o resultado deve ser utilizado em função da aprendizagem do aluno; para refletir e intervir no processo de ensino do professor, enfim. (Prof $\left.{ }^{a} \mathrm{I}\right)$.

Para avaliar as escolas num sentido geral: quantidade de alunos, niveis cognitivos, perfil social, etc., onde serão articuladas estratégias para melhorar o trabalho de todos dentro da escola. A atenção voltada às escolas com menor rendimento deve ser levada para o lado auxiliador e não punitivo. O governo e a instituição escolar devem assumir juntos os resultados. (Prof ${ }^{\mathrm{a}} \mathrm{E}$ ).

Observa-se que as professoras repudiam qualquer forma de classificação e de constrangimento que lhes possa ser imposta. Seus depoimentos nos auxiliam a compreender a proposta formulada por Freitas et al. (2009), no sentido de a avaliação em larga escala, como é o caso da Provinha Brasil, ser articulada à institucional e à avaliação das aprendizagens conduzida em sala de aula. E mais: a avaliação institucional cumpre o papel de mediadora dos dois primeiros níveis: promove o encontro dos dados fornecidos pela avaliação em larga escala e dos obtidos pelos professores em seu trabalho diário para que possam ser analisados por toda a equipe da escola em momentos de avaliação interna. Assim, os autores concebem a avaliação institucional como:

[...] processo de apropriação da escola pelos seus atores, não na visão liberal da "responsabilização" pelos resultados da escola como contraponto da desresponsabilização do Estado pela escola, mas no sentido de que seus atores têm um projeto e um compromisso social, em especial junto às classes populares e, portanto, necessitam, além deste seu compromisso, do compromisso do Estado em relação à educação. (FREITAS et al., 2009, p. 36).

A apropriação dos problemas da escola pelos que nela atuam inclui duas responsabilidades: exigir do Estado as condições necessárias ao seu adequado 
funcionamento e compromisso com as aprendizagens dos estudantes. Esse processo bilateral é denominado pelos autores de qualidade negociada, baseando-se em Bondioli (2004). Essa qualidade resulta de um "pacto" estabelecido com os diferentes segmentos da escola, o que implica uma prática dialógica, constante e efetiva por meio da vivência e da participação de toda comunidade educacional. Ao afirmar que "[...] o governo e a instituição escolar devem assumir juntos os resultados", a professora E refere-se a esse tipo de pacto.

\section{Palavras finais: possíveis contribuições da Provinha Brasil}

No estudo empreendido, partimos do pressuposto de que a Provinha Brasil pode contribuir para a melhoria do processo de ensino-aprendizagem se for compreendida no interior das instituições educacionais e pelas políticas públicas e articulada com a avaliação da aprendizagem via avaliação institucional. Entendemos que a questão central não reside na negação da avaliação externa, mas no uso que se faz dela. Todavia, não desconsideramos que as políticas públicas educacionais e as dinâmicas escolares refletem processos sociais constituídos a partir dos interesses vigentes na sociedade.

Foi possível identificarmos concepções distintas em relação ao uso da Provinha Brasil decorrentes do processo de microrregulação local. Tais concepções revelam que o instrumento ora era tomado como mecanismo de exclusão, com foco no resultado final do teste, ora era tido como um mecanismo de inclusão dentro do espaço escolar, sendo um indicador do processo avaliativo que favorece a tomada de decisão.

Para que a Provinha Brasil cumpra seu propósito diagnóstico e não concorra para a desqualificação do trabalho docente, precisa ser inserida em uma cultura avaliativa que dê ênfase à conquista das aprendizagens por estudantes e professores e despreze atividades e atitudes classificatórias. Cabe destacar que a avaliação formativa, contrariamente à classificatória, propõe-se a promover as aprendizagens não somente dos alunos, mas, também dos professores. Para que estes a compreendam e a pratiquem em benefício das aprendizagens dos estudantes, devem perceber-se em permanente processo de aprendizagem. Este é o realce da avaliação formativa. (VILLAS BOAS, 2011). Como foi apontado no início deste texto, as Diretrizes Pedagógicas do Bloco Inicial de Alfabetização (DISTRITO FEDERAL, 2012) declaram seu compromisso com a adoção da avaliação formativa, o que requer que também a Provinha Brasil a ela se alie pelo fato de ser aplicada às crianças que frequentam o $2^{\circ}$ ano de escolaridade. 
Nenhuma avaliação externa à escola pode ser concebida como uma atividade neutra. Ao contrário, este nível de avaliação interfere diretamente nas relações de avaliação estabelecidas no interior da escola e da sala de aula. É necessário ficarmos atentos para um conjunto de ações mais amplas que são estabelecidas nesse cenário - como a formação de professores e a orientação curricular - e que redefinem também as demais categorias do processo didático que interagem com a avaliação. Surge, assim, a necessidade de termos clareza sobre como e por que são tomadas decisões no âmbito do sistema de ensino, sobre como essas informações são entendidas na escola e como essas decisões expressam relações de poder e definem o tipo de estudante para cuja formação desejou contribuir.

\section{REFERÊNCIAS}

BARROSO, J. O Estado e a educação: a regulação transnacional, a regulação nacional e a regulação local. In: BARROSO, J. (Org.). A regulação das políticas públicas de educação: espaço, dinâmicas e actores. Coimbra: EDUCA; UI\&DCE, 2006. p. 41-70.

BONAMINO, A.; SOUSA, S. Z. Três gerações de avaliação da educação básica: interfaces com o currículo da/na escola. Educação e Pesquisa, v. 38, n. 2, abr./jun. 2012.

BONDIOLI, A. O projeto pedagógico da creche e a sua avaliação: a qualidade negociada. Campinas, SP: Autores Associados, 2004.

DIAS, E. T. G. D. Provinha Brasil e a organização do trabalho pedagógico: percepções de professores alfabetizadores. In: CONGRESSO NACIONAL DE AVALIAÇÃO EM EDUCAÇÃO: I CONAVE, I., 2010, Bauru. Anais... Bauru: CECEMCA/UNESP, 2010. p. 1-14.

DIAS, E. T. G. D. Provinha Brasil e Regulação: Implicações para a Organização do Trabalho Pedagógico. Tese (Doutorado) - Universidade de Brasília, Faculdade de Educação, Brasília, DF, 2014.

DISTRITO FEDERAL. Diretrizes pedagógicas do Bloco Inicial de Alfabetização. Brasília, DF, 2012.

ESTEBAN, T.; SAMPAIO, C. S. Diferença, alteridade e aprendizagem: desafios infantis ao saber docente. In: ENCONTRO NACIONAL DE DIDÁTICA E PRÁTICAS DE ENSINO - ENDIPE, XVI., Campinas, SP, 2012. Anais... Campinas, SP, 2012.

FREITAS, L. C. de. A "progressão continuada" e a "democratização" do ensino. In: VILLAS BOAS, B. M. F. (Org.). Avaliação: políticas e práticas. Campinas, SP: Papirus, 2002. 
FREITAS, L. C. de. Eliminação adiada: o caso das classes populares no interior da escola e a ocultação da (má) qualidade do ensino. Educação \& Sociedade, v. 28, n. 100, p. 965-987, 2007.

FREITAS, L. C. de. Responsabilização, meritocracia e privatização: conseguiremos escapar ao neotecnicismo? In: SEMINÁRIO DE EDUCAÇÃO BRASILEIRA; SIMPÓSIO PNE: DIRETRIZES PARA AVALIAÇÃO E REGULAÇÃO DA EDUCAÇÃO NACIONAL, III., Campinas, SP, 2011. Anais... Campinas, SP: CEDES, 2011. Disponível em: $<$ http://www.cedes.unicamp.br/seminario3/luiz_freitas.pdf $>$. Acesso em: 04 maio 2011.

FREITAS, L. C. de. et al. Avaliação educacional: caminhando pela contramão. Rio de Janeiro: Vozes, 2009.

MAIA, M. Provinha Brasil: a utilização e avaliação dos testes de diagnósticos da alfabetização pelos professores. Dissertação (Mestrado) - Faculdade de Educação, Universidade Federal de Minas Gerais, Belo Horizonte, 2010.

MEC. Provinha Brasil. Portaria Normativa no 10, de 24 de abril de 2007. Disponível em: <http://provinhabrasil.inep.gov.br>. Acesso em: 27 mar. 2013.

VILLAS BOAS, B. M. de F. Compreendendo a avaliação formativa. In: VILLAS BOAS, B. M. de F. (Org.). Avaliação formativa: práticas inovadoras. Campinas, SP: Papirus, 2011.

Texto recebido em 18 de maio de 2015. Texto aprovado em 09 de junho de 2015. 
